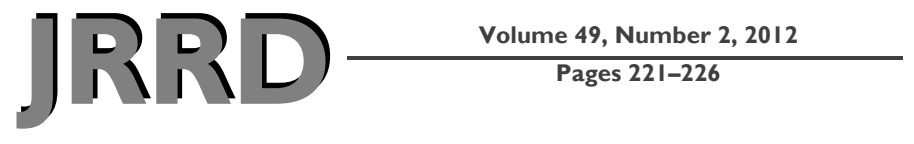

\section{Asymmetric lower-limb bone loss after spinal cord injury: Case report}

\author{
Alison M. Lichy, PT, DPT, NCS; ${ }^{*}$ Suzanne Groah, MD, MPH \\ National Rehabilitation Hospital, Washington, DC
}

\begin{abstract}
Osteoporosis is a significant secondary condition that occurs acutely after spinal cord injury (SCI). This article reports on a patient with motor incomplete SCI and asymmetric lower-limb bone loss as it correlates with lower-limb motor function and gait characteristics. A 32-year-old Caucasian male completed a comprehensive inpatient rehabilitation program, including 3 months of robotic body-weight-supported treadmill training three times a week. Bone mineral density (BMD) was monitored up to 1.5 years post-SCI by dual-energy X-ray absorptiometry. Ground reaction forces were measured through an instrumented treadmill for bilateral weight-bearing comparison. At 1.5 years postinjury, neurological examination revealed thoracic 4 American Spinal Injury Association Impairment Scale D SCI with less strength, reduced weight bearing, and lower BMD in the more neurologically impaired leg. These results suggest that osteoporosis may vary according to severity of impairment within individuals and that monitoring lower-limb BMD is especially important for patients who ambulate.
\end{abstract}

Key words: bone density, DXA, ground reaction forces, lowerlimb motor function, osteoporosis, paraplegia, rehabilitation, robotic-assisted body-weight-supported treadmill training, spinal cord injury, tetraplegia.

\section{INTRODUCTION}

Osteoporosis occurs rapidly after acute spinal cord injury (SCI) [1], with nearly one-third of bone loss occurring within the first 4 months post-SCI and continuing to a lesser degree over the next several years [2]. SCIrelated osteoporosis and osteopenia are characterized by bone loss occurring below the level of injury [3] and in trabecular-rich sites [4-5]. Bone mineral density (BMD) loss tends to be greater in sites more distal from the spine; hence, bone loss is greatest at the os calcis, followed by the proximal tibia and distal femur [6].

The profound bone loss observed is believed to be influenced by the neural lesion, hormonal changes, and immobilization [7-8]. Well-known risk factors for osteoporosis include sex, race/ethnicity, age, family history, sedentary lifestyle, and poor nutrition [9-10]. Garland et al. reported that completeness of injury, low body mass index, and older age were predictors of lower BMD in the SCI population [3]. Completeness of injury may affect BMD through a reduction in weight bearing and mechanical loading [11-12], because those with complete injuries tend to have greater bone loss than those with incomplete injuries [3].

The purpose of this case study was to describe a gentleman with motor incomplete SCI whose primary means of locomotion is ambulation and who has asymmetric lower-limb osteoporosis. We sought to determine whether relationships existed among BMD, lower-limb motor function, and gait pattern.

\footnotetext{
Abbreviations: AFO = ankle-foot orthosis, AIS = American Spinal Injury Association Impairment Scale, BMD = bone mineral density, BWS = body-weight support, DXA = dual-energy X-ray absorptiometry, RABWSTT = robotic-assisted body-weightsupported treadmill training, $\mathrm{SCI}=$ spinal cord injury, $\mathrm{T}=$ thoracic, WISCI-II = Walking Index for Spinal Cord Injury Version 2. *Address all correspondence to Alison M. Lichy, PT, DPT, NCS; 102 Irving St, NW, Washington, DC 20010; 202-8771358; fax: 202-877-7521. Email: Alison.m.lichy@medstar.net http://dx.doi.org/10.1682/JRRD.2011.03.0048
} 


\section{METHODS}

\section{Case Description}

We report on a 32-year-old Caucasian male who was injured in a work-related fall (13 ft), with resultant initial thoracic (T) 4 American Spinal Injury Association Impairment Scale (AIS) [13] A SCI. At the time of injury, he was of average height $(183 \mathrm{~cm})$ and weight $(86.4 \mathrm{~kg})$, with a body mass index of $25.8 \mathrm{~kg} / \mathrm{m}^{2}$, and had no significant medical history and no history of fractures. He underwent open reduction and internal fixation with decompression at T5 and fusion of T4 through T6 with instrumentation, followed by use of a thoracolumbosacral orthosis for 13 weeks. He was transferred to acute inpatient rehabilitation 2 weeks postinjury and completed an 11-week inpatient rehabilitation program. Upon entry to inpatient rehabilitation, the patient had a neurological level of injury of T4 AIS B. At discharge from inpatient rehabilitation, the neurological examination had improved to T4 AIS C (Table 1) and he was ambulating limited household distances using a rolling-walker and an ankle-foot orthosis (AFO) with 1-person assistance. At 4 months post-SCI, he was ambulating using a rolling-walker and AFO independently. At 1.5 years post-SCI, he was independently ambulating with a single-point cane and without an AFO.

Upon discharge from inpatient rehabilitation 11 weeks post-SCI, the participant enrolled in a robotic-assisted bodyweight-supported treadmill training (RABWSTT) study using the Lokomat (Hocoma AG; Volketswil, Switzerland).

\section{Activity Intervention}

The activity intervention consisted of RABWSTT for 1 hour three times a week for 3 months. The initial training speed was $1.9 \mathrm{~km} / \mathrm{h}$ and progressed to $2.5 \mathrm{~km} / \mathrm{h}$ after

Table 1.

Participant's right and left lower-limb American Spinal Injury Association Impairment Scale motor data collected at baseline, 5 months, and 1.5 years post-spinal cord injury.

\begin{tabular}{|c|c|c|c|c|}
\hline \multirow[b]{2}{*}{$\begin{array}{c}\text { Lower-Limb } \\
\text { Muscle }\end{array}$} & \multirow[b]{2}{*}{$\begin{array}{l}\text { Spinal } \\
\text { Root }\end{array}$} & \multirow{2}{*}{$\begin{array}{c}\text { Right } \\
\text { Baseline, } \\
5 \text { mo, and } \\
1.5 \text { yr }\end{array}$} & \multicolumn{2}{|c|}{ Left } \\
\hline & & & $\begin{array}{c}\text { Baseline } \\
\text { and } 5 \mathrm{mo}\end{array}$ & $1.5 \mathrm{yr}$ \\
\hline Iliopsoas & L2 & 5 & 2 & 4 \\
\hline Quadriceps & L3 & 5 & 2 & 2 \\
\hline Tibialis anterior & L4 & 4 & 2 & 2 \\
\hline Gastrocnemius & S1 & 4 & 1 & 1 \\
\hline
\end{tabular}

3 months. During the sessions, the amount of body-weight support (BWS) and robotic assistance were decreased as tolerated to increase weight bearing and workload toward the goal of the participant ambulating without BWS. The participant varied in the BWS required to ambulate throughout his training sessions from 16 to $32 \mathrm{~kg}$ BWS. This variability was based on the participant's fatigue level during the training session.

\section{Outcome Measurements and Analyses}

Outcome measures were obtained at baseline (11 weeks post-SCI), 5 months postinjury, and 1.5 years postinjury and included the standardized AIS examination, the Walking Index for Spinal Cord Injury Version 2 (WISCI-II) [14], and BMD via dual-energy X-ray absorptiometry (DXA). At the 1.5-year postinjury follow-up, a weightbearing analysis was conducted. All assessments (excluding DXA) were conducted by a study physical therapist.

BMD (reported in grams per centimeter squared) was obtained by DXA using the Lunar Prodigy Bone Densitometry System (Lunar Corporation; Madison, Wisconsin). Measurements were taken of the lumbar spine and bilateral femoral neck, distal femur, and proximal tibia. The modified lumbar protocol was applied to the distal femur and proximal tibia [15]. One blinded DXA technologist was trained on this protocol and performed all testing and participant setup. DXA measurements were taken of the lumbar and bilateral femoral neck at baseline, followup, and 1.5 years. Bilateral measurements of the distal femur and proximal tibia were taken only at the 1.5-year follow-up.

Ambulatory weight-bearing analysis was conducted through the use of an ADAL3D-F/COP/Mz instrumented split-belt treadmill, with each belt of the treadmill mounted on four Kistler triaxial piezoelectric sensors (Winterthur, Switzerland). To determine the tested walking speed, we increased the speed of the treadmill until the participant noted a comfortable self-selected speed. The subject was instructed to walk at his self-selected speed as he would normally walk, and he was allowed to use the side rails for weight support through the upper limbs as needed. Thirty seconds of data were recorded, including ground reaction forces in the vertical, anteriorposterior, and medial-lateral planes.

This data-collection process was repeated at selected speeds below and above the self-selected walking speed. 


\section{RESULTS}

Table 1 shows the changes in motor function in the lower limbs between the 11-week, 5-month, and 1.5-year time points. No change in AIS motor scores occurred between 11 weeks, 5 months, and 1.5 years postinjury on the right, though hip flexion strength of the left lower limb improved, as seen in Table 1.

WISCI-II scores increased from a baseline score of 6 (using a rolling-walker and left AFO with 1-person assistance) to a 10 (ambulating with a rolling-walker) at 5 months and to a 19 (ambulating independently using a single-point cane) at 1.5 years post-SCI.

Gait analysis performed at the 1.5-year time point is shown in Figure 1. Vertical ground reaction forces exerted were calculated as a fraction of body weight, first at $2.0 \mathrm{~km} / \mathrm{h}$ (calculated self-selected speed), followed by $2.5 \mathrm{~km} / \mathrm{h}$ and $1.5 \mathrm{~km} / \mathrm{h}$. Peak vertical forces measured at $1.5 \mathrm{~km} / \mathrm{h}$ were 77 percent on the left leg and 89 percent on the right leg. At $2.0 \mathrm{~km} / \mathrm{h}$, peak vertical forces were 81 percent on the left leg and 88 percent on the right leg. At $2.5 \mathrm{~km} / \mathrm{h}$, peak vertical forces were 83 percent on the left leg and 89 percent on the right leg.

Table 2 shows the loss of BMD in the lower limbs over time. Over the study period, the lumbar spine had a 2.77 percent loss of BMD (1.119 to $1.147 \mathrm{~g} / \mathrm{cm}^{2}$ ), the right proximal femur had a 3.96 percent loss of BMD (0.934 to $0.887 \mathrm{~g} / \mathrm{cm}^{2}$ ), and the left proximal femur had a 10.52 percent loss of BMD (0.922 to $0.745 \mathrm{~g} / \mathrm{cm}^{2}$ ).

At the 1.5 year time point, additional DXA measurements at the distal femur and proximal tibia revealed higher BMD in the right lower limb than the left lower limb (Figure 2). According to World Health Organization cutoffs [16], the right distal femur would be classified as osteopenic (T-Score: -1.5 ) and the left distal femur would be considered osteoporotic (T-score: -3.0 ).

\section{DISCUSSION}

The objective of this study was to describe asymmetric BMD loss following an incomplete SCI and discuss the implications for rehabilitation. This case demonstrates an ambulatory gentleman with motor incomplete SCI and greater motor impairment in the left lower limb than the right lower limb. As would be expected, he bears weight to a lesser extent through the weaker limb. Likewise, BMD was markedly reduced in the more impaired leg from baseline to 1.5 years post-SCI.

This case is the first to describe asymmetric bone loss in a patient with SCI. These findings are similar to those observed in the stroke population, in which a significantly

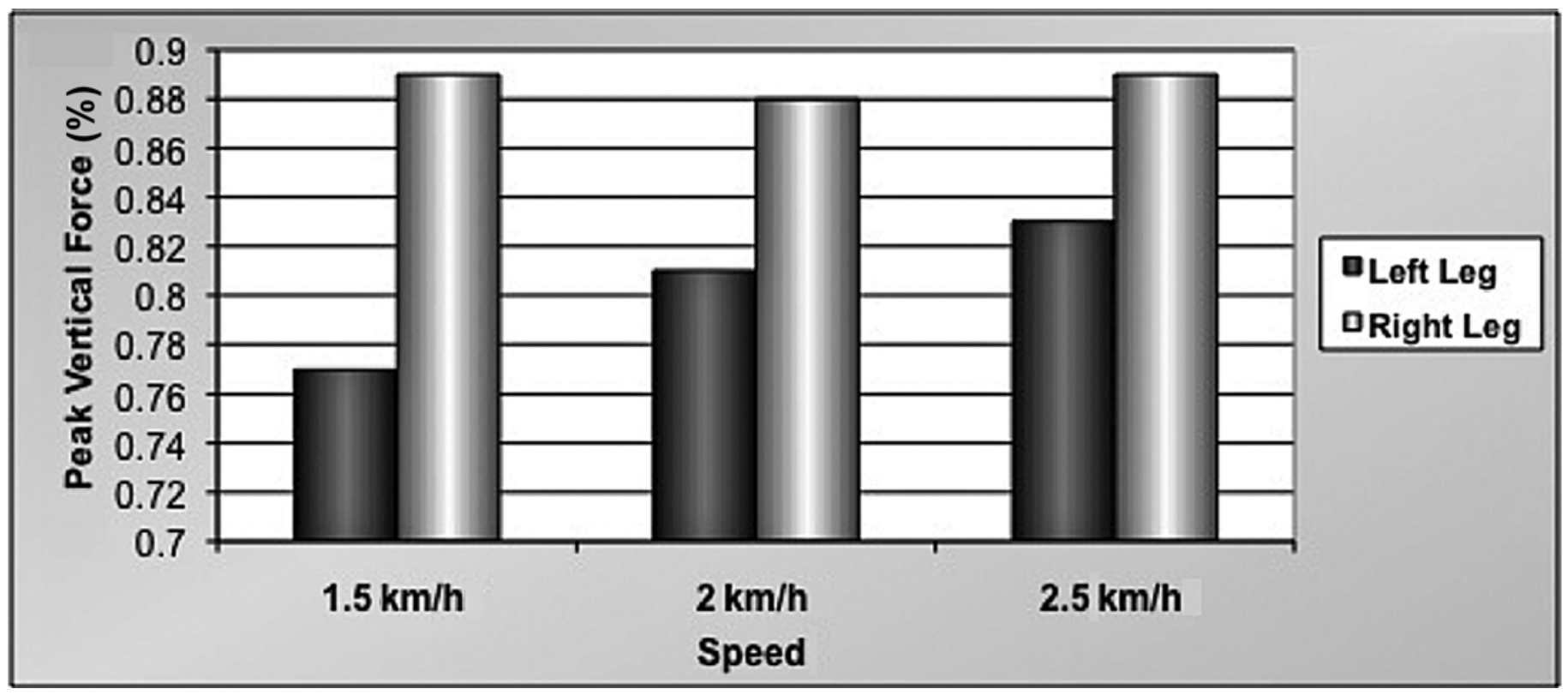

Figure 1.

Peak ground reaction forces of right and left while walking at various speeds: slow (1.5 km/h), self-selected (2 km/h), and fast (2.5 km/h). 
JRRD, Volume 49, Number 2, 2012

Table 2.

Participant's bone mineral density loss from baseline to 1.5 years post-spinal cord injury at lumbar spine and hips.

\begin{tabular}{|c|c|c|c|}
\hline Examination & $\begin{array}{c}\text { Lumbar } \\
\left(\mathrm{g} / \mathrm{cm}^{2}\right)\end{array}$ & $\begin{array}{c}\text { Left Proximal } \\
\text { Femur } \\
\left(\mathrm{g} / \mathrm{cm}^{2}\right)\end{array}$ & $\begin{array}{c}\text { Right Proximal } \\
\text { Femur } \\
\left(\mathrm{g} / \mathrm{cm}^{2}\right)\end{array}$ \\
\hline Baseline & 1.119 & 0.922 & 0.934 \\
\hline $5 \mathrm{mo}$ & 1.088 & 0.825 & 0.897 \\
\hline $1.5 \mathrm{yr}$ & 1.147 & 0.745 & 0.887 \\
\hline
\end{tabular}

greater loss of bone occurs in the paretic side than the nonparetic side [17]. This difference has been correlated with muscle strength [18], motor recovery [19], ability to ambulate, and amount of loading [20]. BMD loss is also seen in the nonparetic side in chronic stroke, which may be the result of changes in use and weight-bearing patterns. In chronic stroke, an exercise program [21] with emphasis on lower-limb weight bearing and treadmill gait training [22] benefited BMD in the paretic leg. Analogous, muscle activity and ground reaction forces produced through ambulation may provide mechanical strain necessary to maintain BMD in SCI, as seen in recent studies in chronic stroke [21-22].

A recent study by Dudley-Javorski and Shields suggests the importance of the orientation of muscular contraction on bone retention, because electrical stimulation of the soleus muscle was associated with significantly higher BMD in the posterior tibia compared with the unstimulated anterior tibia, which did not differ significantly in BMD of chronic SCI [12]. These results provide further support for Dudley-Javorski and Shields' finding that mechanical loading was an important intervention for bone loss attenuation [23].

A limitation of this study is that ground reaction force data were not collected during the RABWSTT. The goal during RABWSTT was gait symmetry with increased weight bearing through the lower limbs as tolerated. The lack of ground reaction force data raises the potential that the goal of symmetrical weight bearing during RABWSTT could have delayed BMD loss. However, without ground reaction force data at the 5-month follow-up, we are unable to determine the amount of loading of the lower limbs bilaterally or the effects of mechanical loading through RABWSTT.

There is a paucity of data on the effects of differential BMD in incomplete SCI and the effects on upright activities of standing and ambulating when considering fracture thresholds. Differential osteoporosis is physiologically plausible and we have shown that it occurs in SCI similar to stroke. Clinicians need to have a high index of suspicion for bone loss even in those who primarily ambulate. This information is also critical to therapists designing activity

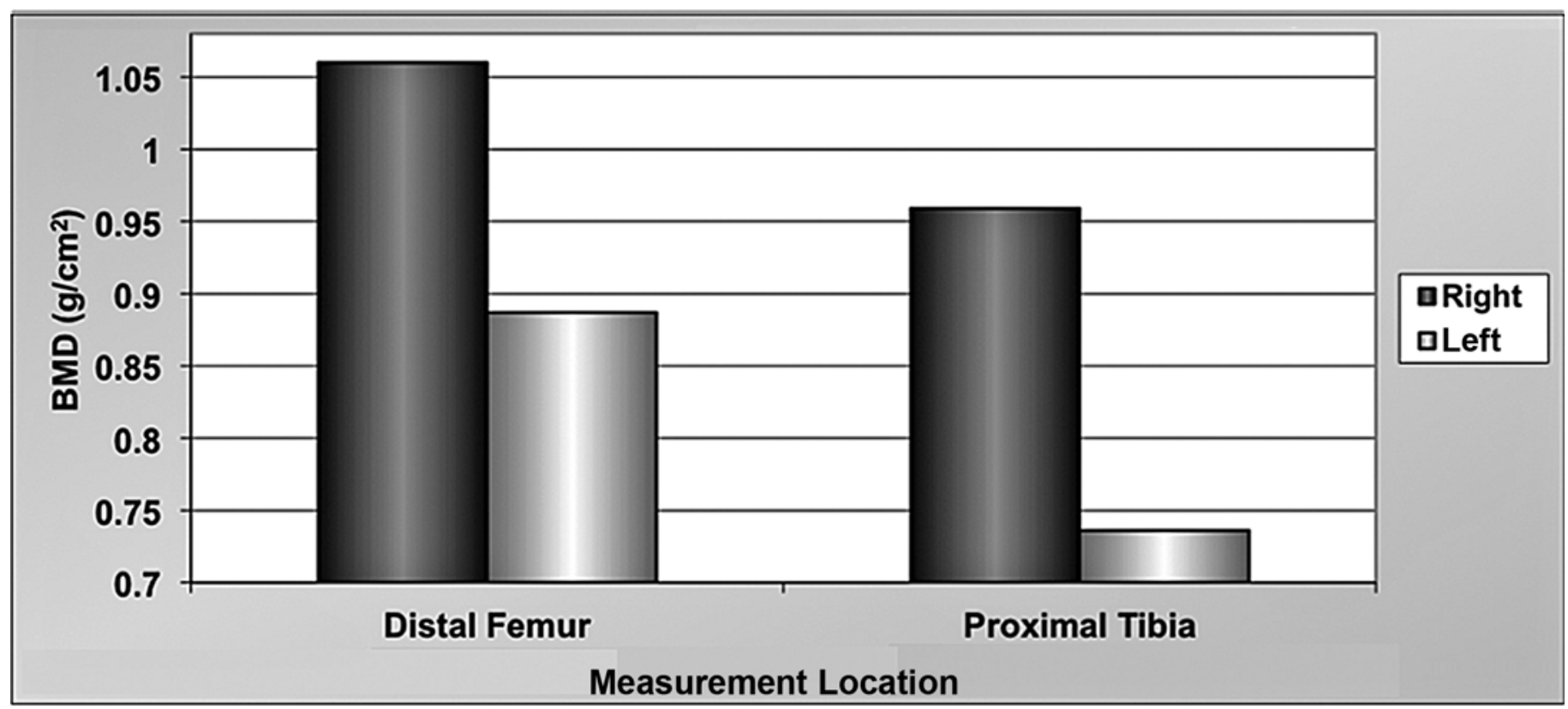

Figure 2.

Dual-energy X-ray absorptiometry measurements of bilateral knees at 1.5-year follow-up. BMD = bone mineral density. 
protocols for those with incomplete SCI who are ambulating or pursuing other upright activity. Pharmacological treatment in asymmetric osteoporosis may also be considered.

\section{CONCLUSIONS}

We presented the case of an individual with asymmetric lower-limb motor function and gait pattern due to SCI, both of which may have combined to result in asymmetric BMD loss. This case demonstrates the need to monitor BMD even in ambulatory individuals with SCI. Some ambulatory individuals with SCI may benefit from treatment to reduce BMD loss and avoid the risk of fractures.

\section{ACKNOWLEDGMENTS}

\section{Author Contributions:}

Principal Investigator: A. Lichy (study, 2007-2010), S. Groah (National Institute on Disability and Rehabilitation Research grant). Initial study design: A Lichy, S. Groah.

Proposal process: A Lichy.

Drafting of manuscript: A. Lichy, S. Groah.

Data interpretation: A. Lichy.

Financial Disclosures: The authors have declared that no competing interests exist.

Funding/Support: This material was based on work supported by National Institute on Disability and Rehabilitation Research grants (H133B0331114 and H133B090002) to the National Rehabilitation Hospital Rehabilitation Research and Training Center in the Rehabilitation of Individuals with Spinal Cord Injury.

Additional Contributions: Joseph Hidler, $\mathrm{PhD}$, for the assistance he provided in data collection for gait analysis.

Institutional Review: The institutional review board of Medstar Research Institute approved this study, and the participant provided informed consent prior to participation.

Participant Follow-Up: The authors do not plan to inform the participant of the publication of this study.

\section{REFERENCES}

1. Garland DE, Stewart CA, Adkins RH, Hu SS, Rosen C, Liotta FJ, Weinstein DA. Osteoporosis after spinal cord injury. J Orthop Res. 1992;10(3):371-78. PMID: 1569500 http://dx.doi.org/10.1002/jor.1100100309

2. Biering-Sørensen F, Bohr HH, Schaadt OP. Longitudinal study of bone mineral content in the lumbar spine, the forearm and the lower extremities after spinal cord injury. Eur $\mathrm{J}$ Clin Invest. 1990;20(3):330-35. PMID: 2114994
3. Garland DE, Adkins RH, Rah A, Stewart CA. Bone loss with aging and the impact of SCI. Topics Spinal Cord Inj Rehabil. 2001;6(3):47-60.

http://dx.doi.org/10.1310/5W45-0L5B-8C7B-C93T

4. Modlesky CM, Majumdar S, Narasimhan A, Dudley GA. Trabecular bone microarchitecture is deteriorated in men with spinal cord injury. J Bone Miner Res. 2004;19(1):48-55.

PMID: 14753736

http://dx.doi.org/10.1359/jbmr.0301208

5. Jiang SD, Jiang LS, Dai LY. Changes in bone mass, bone structure, bone biomechanical properties, and bone metabolism after spinal cord injury: A 6-month longitudinal study in growing rats. Calcif Tissue Int. 2007;80(3):167-75.

PMID: 17340221

http://dx.doi.org/10.1007/s00223-006-0085-4

6. Garland DE, Adkins RH, Scott M, Singh H, Massih M, Stewart C. Bone loss at the os calcis compared with bone loss at the knee in individuals with spinal cord injury. J Spinal Cord Med. 2004;27(3):207-11. PMID: 15478521

7. Bauman WA, Spungen AM, Wang J, Pierson RN Jr, Schwartz E. Continuous loss of bone during chronic immobilization: A monozygotic twin study. Osteoporos Int. 1999; 10(2):123-27. PMID: 10501792 http://dx.doi.org/10.1007/s001980050206

8. Maïmoun L, Fattal C, Micallef JP, Peruchon E, Rabischong P. Bone loss in spinal cord-injured patients: From physiopathology to therapy. Spinal Cord. 2006;44(4):203-10. PMID: 16158075 http://dx.doi.org/10.1038/sj.sc.3101832

9. Coin A, Sergi G, Benincà P, Lupoli L, Cinti G, Ferrara L, Benedetti G, Tomasi G, Pisent C, Enzi G. Bone mineral density and body composition in underweight and normal elderly subjects. Osteoporos Int. 2000;11(12):1043-50.

PMID: 11256896 http://dx.doi.org/10.1007/s001980070026

10. Riggs BL, Wahner HW, Seeman E, Offord KP, Dunn WL, Mazess RB, Johnson KA, Melton LJ 3rd. Changes in bone mineral density of the proximal femur and spine with aging. Differences between the postmenopausal and senile osteoporosis syndromes. J Clin Invest. 1982;70(4):716-23. PMID: 7119111 http://dx.doi.org/10.1172/JCI110667

11. Rittweger J, Gerrits K, Altenburg T, Reeves N, Maganaris $\mathrm{CN}$, De Haan A. Bone adaptation to altered loading after spinal cord injury: A study of bone and muscle strength. J Musculoskelet Neuronal Interact. 2006;6(3):269-76.

PMID: 17142949

12. Dudley-Javoroski S, Shields RK. Asymmetric bone adaptations to soleus mechanical loading after spinal cord injury. J Musculoskelet Neuronal Interact. 2008;8(3):227-38. PMID: 18799855 
13. American Spinal Injury Association. Reference manual of the international standards for neurological classification of spinal cord injury. Chicago (IL): American Spinal Injury Association; 2003.

14. Dittuno PL, Ditunno JF Jr. Walking index for spinal cord injury (WISCI II): Scale revision. Spinal Cord. 2001; 39(12):654-56. PMID: 11781863 http://dx.doi.org/10.1038/sj.sc.3101223

15. Shields RK, Schlechte J, Dudley-Javoroski S, Zwart BD, Clark SD, Grant SA, Mattiace VM. Bone mineral density after spinal cord injury: A reliable method for knee measurement. Arch Phys Med Rehabil. 2005;86(10):1969-73. PMID: 16213240 http://dx.doi.org/10.1016/j.apmr.2005.06.001

16. WHO Scientific Group on the Assessment of Osteoporosis at Primary Health Care Level; 2004 May 5-7; Brussels, Belguim; Geneva (Switzerland): WHO Press, World Health Organization; 2007.

17. Worthen LC, Kim CM, Kautz SA, Lew HL, Kiratli BJ, Beaupre GS. Key characteristics of walking correlate with bone density in individuals with chronic stroke. J Rehabil Res Dev. 2005;42(6):761-68. PMID: 16680613 http://dx.doi.org/10.1682/JRRD.2005.02.0036

18. Pang MY, Eng JJ, McKay HA, Dawson AS. Reduced hip bone mineral density is related to physical fitness and leg lean mass in ambulatory individuals with chronic stroke. Osteoporos Int. 2005;16(12):1769-79. PMID: 15902416 http://dx.doi.org/10.1007/s00198-005-1925-1

19. Yavuzer G, Ataman S, Süldür N, Atay M. Bone mineral density in patients with stroke. Int J Rehabil Res. 2002; 25(3):235-39. PMID: 12352178 http://dx.doi.org/10.1097/00004356-200209000-00010

20. Jørgensen L, Crabtree NJ, Reeve J, Jacobsen BK. Ambulatory level and asymmetrical weight bearing after stroke affects bone loss in the upper and lower part of the femoral neck differently: Bone adaptation after decreased mechanical loading. Bone. 2000;27(5):701-7. PMID: 11062359

http://dx.doi.org/10.1016/S8756-3282(00)00374-4

21. Pang MY, Ashe MC, Eng JJ, McKay HA, Dawson AS. A 19-week exercise program for people with chronic stroke enhances bone geometry at the tibia: A peripheral quantitative computed tomography study. Osteoporos Int. 2006; 17(11):1615-25. PMID: 16896509 http://dx.doi.org/10.1007/s00198-006-0168-0

22. Pang MY, Lau RW. The effects of treadmill exercise training on hip bone density and tibial bone geometry in stroke survivors: A pilot study. Neurorehabil Neural Repair. 2010; 24(4):368-76. PMID: 19959830 http://dx.doi.org/10.1177/1545968309353326

23. Dudley-Javoroski S, Shields RK. Muscle and bone plasticity after spinal cord injury: Review of adaptations to disuse and to electrical muscle stimulation. J Rehabil Res Dev. 2008;45(2):283-96. PMID: 18566946 http://dx.doi.org/10.1682/JRRD.2007.02.0031

Submitted for publication March 17, 2011. Accepted August 9, 2011.

This article and any supplementary material should be cited as follows:

Lichy AM, Groah S. Asymmetric lower-limb bone loss after spinal cord injury: Case report. J Rehabil Res Dev. 2012;49(2):221-26.

http://dx.doi.org/10.1682/JRRD.2011.03.0048

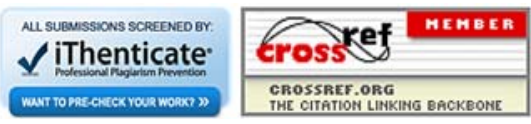

